\title{
ensino de solo na Geografia a partir da prática em campo
}

\author{
The teaching of soil in Geography from field practice
}

\begin{abstract}
Juvenal Severino Botelho (iD https://orcid.org/0000-0002-3709-8617
Instituto Federal de Educação, Ciência e Tecnologia do Amazonas (IFAM) e-mail - advjuvenal@bol.com.br
\end{abstract}

Jean Dalmo de Oliveira Marques (i) https://orcid.org/0000-0002-8920-0919

Instituto Federal de Educação, Ciência e Tecnologia do Amazonas (IFAM)

e-mail -jdomarques@hotmail.com

\section{Resumo}

O objetivo do presente estudo foi desenvolver o ensino de origem, formação, ocupação, erosão e preservação do solo na geografia a partir de práticas de campo, observando suas contribuições para o processo de ensino-aprendizagem a partir das experiências vivenciadas. A pesquisa foi do tipo qualitativa e desenvolvida a partir da realização de atividades interventivas caracterizadas por aulas expositivas dialogadas e atividades práticas de campo. Os instrumentos de coleta de dados utilizados foram questionários, roteiros norteadores e avaliações realizadas ao longo da trajetória da pesquisa. As práticas em campo de caráter investigativo, exploratório e interdisciplinar possibilitaram o ensino de origem, formação, ocupação, erosão e preservação do solo de forma prática, em campo, permitindo aos estudantes compreenderem os processos, transformações e interações que regem essas temáticas, impossíveis de serem compreendidas apenas em sala de aula. Os professores precisam conduzir o ensino a partir de um processo dinâmico e não isolado em conceitos específicos da ciência do solo, mas contextualizado com a paisagem e com os fatores e processos atuantes.

Palavras-chave: Solo. Ensino-aprendizagem. Prática de campo.

\section{Abstract}

The objective of this study was to develop the teaching of origin, formation, occupation, erosion and soil preservation in Geography from field practices, observing their contributions to the teaching-learning process from the lived experiences. The research was qualitative and developed from the performance of interventional activities characterized by expository classes and activated field practices. The data collection instruments used were questionnaires, guiding scripts and evaluations carried out along the research trajectory. Investigative, exploratory and interdisciplinary field practices made it possible to teach soil origin, formation, occupation, erosion and preservation in a practical way in the field, allowing students to understand the processes, transformations and interactions that rules these themes, impossible to understand only in the classroom. Teachers need to conduct 
teaching from a dynamic process not isolated in specific concepts of soil science, but contextualized with the landscape and the factors and processes at work.

Keywords: Soil. Teaching-learning. Field practice.

\section{Introdução}

A preocupação do Ensino de Geografia está no processo de ensinar e aprender as dinâmicas e fenômenos que regem o espaço, favorecendo a aprendizagem e a construção do pensamento geográfico (ALVES; SOUZA, 2015). No mesmo sentido, a Geografia como ciência possibilita o desenvolvimento consciente dos sujeitosalunos quanto às práticas sociais na configuração das espacialidades geográficas locais e globais, favorecendo-os a compreensão crítica de espaço, frente ao atual processo de globalização socioeconômica e cultural. A Educação Geográfica, sob esse foco, é uma área curricular que capacita os educandos a decodificar a realidade e desenvolver o entendimento do mundo na sua complexidade e orientálos a construir a sua cidadania ativa na sociedade (PRADO; CARNEIRO, 2017). Atualmente, o ensino de Geografia é alvo de densas reflexões e amplos debates acerca do seu papel na formação da cidadania ativa, participativa e da importância dessa disciplina no contexto escolar (ARRUDA, 2019).

Nessa perspectiva, o ensino de solos recebe uma atenção especial devido estar relacionado diariamente com a vida acadêmica, social e econômica dos estudantes. Isso é percebido facilmente pela localização geográfica das escolas edificadas sobre esse recurso natural, pelas ações realizadas em termos de sua preservação e ou conservação e pelo que ele nos proporciona quanto à produção de alimentos. De modo geral, as pessoas têm uma atitude de pouca consciência e sensibilidade em relação ao solo, o que contribui para sua degradação, seja pelo mau uso, seja pela sua ocupação desordenada. A problemática em torno da conservação do solo é na maioria dos casos, negligenciada. A consequência disso é o crescimento contínuo dos problemas ambientais ligados à degradação do solo, tais como: erosão, poluição, deslizamentos, assoreamento de cursos de água etc (MUGGLER; SOBRINHO; MACHADO, 2006).

Por outro lado, o ensino desse recurso natural na geografia ainda carece de metodologias que, além de transmitir informações, possam proporcionar conhecimentos que fortaleçam a consciência ambiental, solidificando a cidadania. Assim, ao considerar a importância do estudo das metodologias aplicadas aos conteúdos da Geografia, percebe-se a necessidade de uma estreita relação entre teoria e prática (SOUSA; JUNIOR; ALBUQUERQUE, 2019), principalmente, quanto ao ensino de solo. Sousa e Albuquerque (2017) mencionam que os professores atualmente buscam metodologias diferentes dos modelos tradicionais com a finalidade de instigar os alunos a se tornarem agentes participativos no processo de ensino/aprendizagem e fazer com que estes se motivem e se interessem quanto à importância desta disciplina no âmbito escolar e na vida cotidiana. 
Dessa forma, as atividades em campo são importantes instrumentos metodológicos na formação de professores de Geografia, a julgar pela relação da construção da ação docente com a prática pedagógica. Como necessidade e proximidade com o campo de atuação, as escolas de formação de professores de Geografia fazem uso dessa metodologia para dinamizar a formação docente com vistas ao desenvolvimento da práxis em sala de aula e em campo (NUNES; DE SOUSA; VIANA, 2018).

Assim, a disciplina de Geografia não deve ser identificada em estudos e análises limitadas ao livro didático e à sala de aula, mas sim, em uma disciplina "[.....] enfatize o diálogo, professor-aluno e aluno-aluno, abordando uma temática renovada, com reflexões, críticas e pontos de vistas a serem discutidos entres os mesmos" (BRAGA; OLIVEIRA; MORAIS, 2017, p. 18). Ao utilizar novos recursos metodológicos estamos contribuindo com o fazer pedagógico do professor, pois ele tem o poder de dinamizar a sala de aula, saindo de um ambiente monótono, no qual um fala e todos escutam, para um ambiente acolhedor, dinâmico com possibilidades de discussões e debates (FREITAS, 2018).

O objetivo do presente estudo foi desenvolver o ensino de origem, formação, ocupação, erosão e preservação do solo na geografia a partir de práticas de campo, observando suas contribuições para o processo de ensino-aprendizagem a partir das experiências vivenciadas. A premissa desta pesquisa é que essas temáticas só são realmente compreendidas por meio de práticas em campo, pois permitem que os alunos tenham um contato direto com os processos, transformações e interações naturais ou antrópicas que ocorrem no meio em que vivem, propiciando uma experiência capaz de desvendar o mundo acerca da interação teoria e prática.

\section{Procedimentos metodológicos}

Esta pesquisa foi realizada no Instituto Federal de Educação, Ciência e Tecnologia do Amazonas, Campus Manaus-Centro (IFAM/CMC) e em áreas urbanas do município de Manaus-AM. Foi desenvolvida com a participação de 40 alunos do $1^{\circ}$ ano, do Curso Técnico de Nível Médio Integrado, que têm nas suas ementas curriculares a disciplina de Geografia, tendo o solo como parte integrante dos conteúdos ministrados. A escolha dos alunos ocorreu por meio de amostra casual simples, a partir de sorteios, porém, antes foi explicado a eles do que se tratava a pesquisa, seus objetivos e importância e, posteriormente, por serem menores de idade, foi comunicado aos pais e/ou responsáveis sobre a participação dos mesmos no projeto, com a devida formalização do Termo de Consentimento Livre e Esclarecido - TCLE.

A pesquisa consistiu numa investigação qualitativa que de acordo com Bogdan e Biklen (1994) tem o ambiente natural como fonte direta dos dados, preocupando-se com o processo e não simplesmente com o resultado e/ou produto obtido. Foram utilizados questionários diagnóstico e final como instrumentos investigativos (GODOY, 1995) aplicados aos alunos contendo questões abertas e fechadas como 
forma de avaliar os conhecimentos prévios e adquiridos em relação às temáticas estudadas.

As atividades interventivas foram caracterizadas por aulas expositivas dialogadas e práticas de campo. O diálogo entre educador e educando foram interligados, o que permite a ocorrência de percepções críticas e conscientização. As aulas expositivas dialogadas não integram a pesquisa enquanto geradora de dados, mas como suporte para o fortalecimento e embasamento teórico para as práticas de campo. As aulas foram de 50 (cinquenta) minutos, cada tempo, visando preparar os alunos para as práticas de campo, proporcionando o embasamento teórico necessário para a compreensão sobre origem, formação, ocupação, erosão e preservação do solo, sendo ministradas em 10 (dez) tempos de aulas, em dias intercalados. Os recursos utilizados no decorrer da aula foram quadro branco, pincel, datashow e maquete. As temáticas foram expostas e discutidas em relação aos conceitos, origem, importância, processo e alternativas de preservação. As práticas de campo foram realizadas em 08 (oito) tempos de aulas, sendo 04 (quatro) tempos para cada turma, com caráter investigativo, exploratório e interdisciplinar. Utilizou-se a abordagem geossistêmica (BERTRAND, 1968) como forma de proporcionar uma visão integrada dos elementos que compõem o ambiente com a incorporação da ação social na interação com o potencial ecológico, exploração biológica e atividades socioeconômicas e culturais (NASCIMENTO; SAMPAIO, 2005). Segundo Guerra, Souza e Lustoza, (2012, p. 1):

\begin{abstract}
A Teoria Geossistêmica como aporte teórico-metodológico urge a luz da Teoria Geral dos Sistemas, como potencialidade para a construção de uma nova geografia, antes disparatada em conhecimentos desconexos. A partir da década de 1960 com as sistematizações pioneiras de Victor Sotchava e, posteriormente, as de Georges Bertrand, instituem-se novos paradigmas à Geografia, por sua vez, ungidos na perspectiva de integração e construção de uma ciência.
\end{abstract}

Com esta perspectiva, primando pela unicidade da Geografia Física e da Geografia Humana, a pesquisa ocorreu em todo o seu percurso considerando a conexão dos diversos elementos constituintes dos aspectos físico-naturais nos quais o solo está inserido. Assim, foi possível trabalhar o embasamento teórico para a compreensão sobre origem, formação, ocupação, erosão e preservação do solo de uma forma prática, onde foram utilizados roteiros de prática de campo sobre cada conteúdo abordado para orientar os alunos quanto às observações necessárias a serem realizadas. Dentre as orientações contidas no roteiro, destacavam-se: a) registrar as características do ambiente por meio de fotos quanto à existência e localização de rocha, solo, vegetação, água; b) identificar os fatores que influenciam na formação do solo seus horizontes e as diferenças entre eles; c) identificar as classes de solos que existiam no local; d) identificar processos erosivos suas causas e consequências para a qualidade ambiental; e) a atual situação das encostas e o que fazer para preservá-las e f) o que fazer para evitar deslizamentos nas encostas.

Os locais utilizados como percurso das práticas de campo sobre solos foram: a) Ponta das Lajes, localizada na parte central da Bacia do Amazonas, coordenadas $03^{\circ} 08^{\prime} \mathrm{S}$ e $59^{\circ} 52^{\prime} \mathrm{W}$, na margem esquerda do Rio Amazonas, cerca de $20 \mathrm{~km}$ ao 
oeste do Rodway, porto do centro histórico da cidade de Manaus no Rio Negro, e 2 $\mathrm{km}$ à jusante da confluência dos rios Negro e Solimões especificamente no Centro de Projetos e Estudos Ambientais do Amazonas da Associação Brasil Soka Gakkai, na Avenida Desembarcador Anísio Jobin 980, Km 11 (FRANZINELLI; IGREJA, 2013) e b) Distrito Industrial - 2, em uma sequência localizada ao longo da estrada do Puraquequara que dá acesso a Colônia Antônio Aleixo, coordenadas 0303'22"S e $59^{\circ} 53^{\prime} 38^{\prime \prime} \mathrm{W}$

A tabulação dos dados e análise dos resultados obtidos foi realizado classificandose as respostas quanto ao conhecimento inicial $(\mathrm{Cl})$ e final (CF) em: Sim; Não; resposta satisfatória (RS), que representaram respostas embasadas na literatura utilizada durante as aulas teóricas e resposta não satisfatória (RNS), que representaram ausência de base conceitual, tautológicas e não embasadas na literatura utilizada durante as aulas teóricas e práticas de campo. Além disso, algumas respostas foram agrupadas nas categorias: preservacionistas, conservacionistas, pedológica ou geomorfológica.

\section{Resultados e Discussões}

A análise geral dos resultados obtidos a partir da comparação do $\mathrm{Cl}$ e CF demonstrou uma contribuição positiva da prática de campo desenvolvida (Figuras 1 $a, b, c e d)$.

Figuras 1 a, b, c e d - Respostas obtidas sobre o conhecimento inicial (Cl) e final (CF), após a aplicação dos questionários. RS representa resposta satisfatória e RNS resposta não satisfatória.

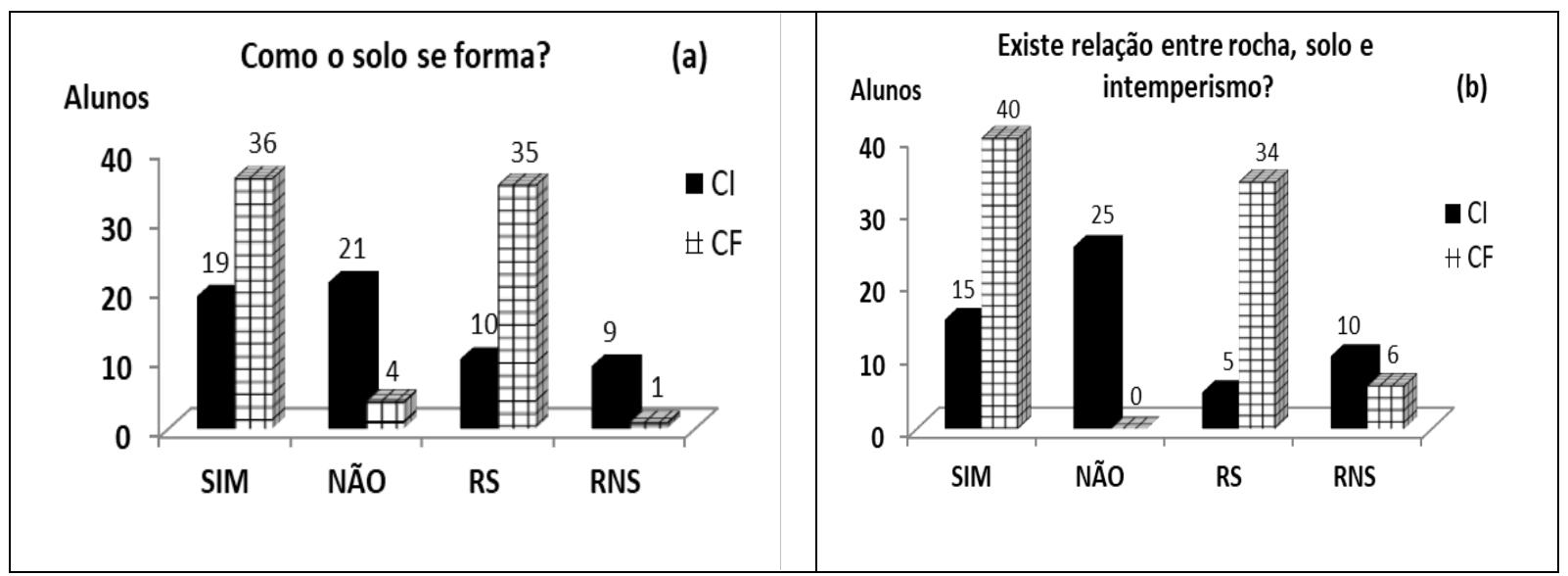




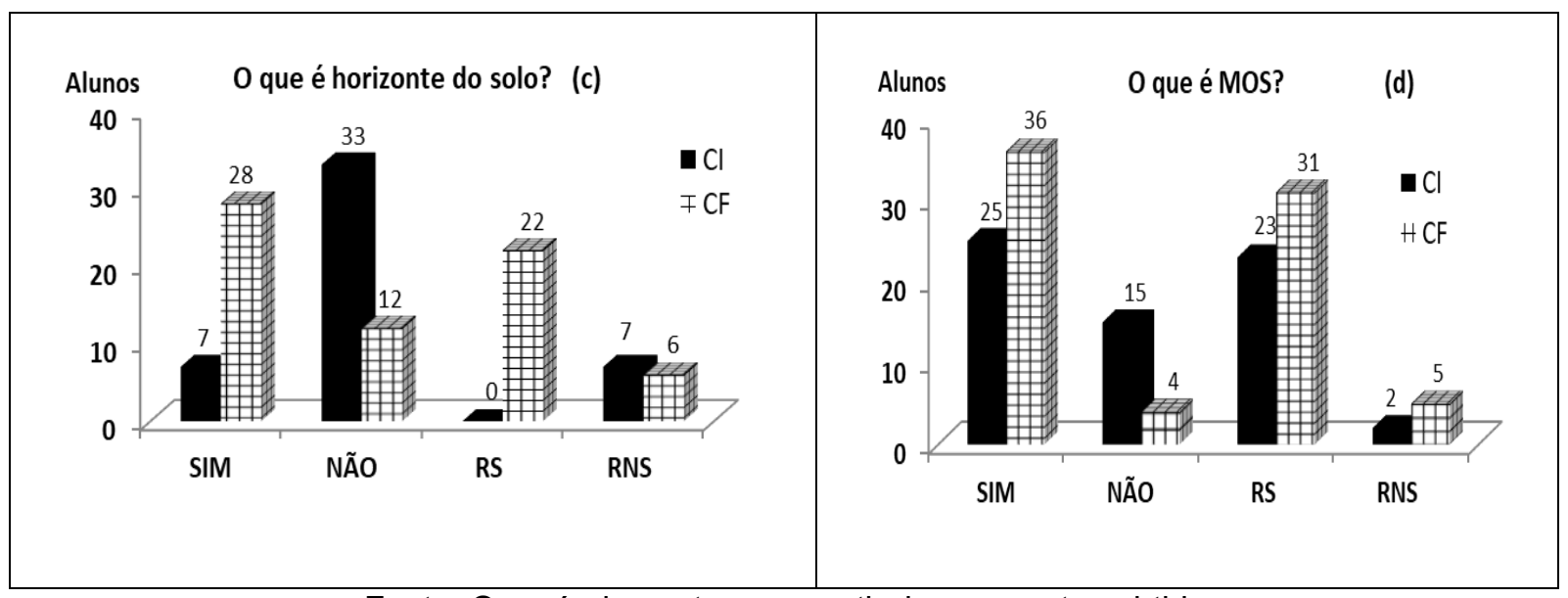

Fonte: Os próprios autores a partir das respostas obtidas.

Resultados mais expressivos foram obtidos nas questões que indagavam: a relação existente entre rocha, solo e intemperismo (Figura 1b), como o solo se forma (Figura 1a) e o que é matéria orgânica do solo (MOS) (Figura 1d). A maior dificuldade inicial foi observada na questão sobre horizonte do solo, onde 33 não sabiam respondê-la (Figura 1c). Na realidade, a compreensão sobre horizonte do solo só é obtida a partir de uma evolução conceitual lógica de todos os fatores e processos que envolvem a origem e formação do solo, sendo função do professor buscar a melhor forma de abordar o tema com os alunos. Após a identificação e reconhecimento dos horizontes do solo, foi possível obter um resultado satisfatório após a realização do trabalho de campo, onde 28 alunos (Figura 1c) disseram entender o conceito de horizonte do solo, dentre os quais 22 alunos apresentaram resposta satisfatória quanto ao conceito elaborado.

As 34 respostas satisfatórias obtidas dos 40 alunos que responderam existir uma relação entre rocha, solo e intemperismo (Figura 1B) deixa claro a importância da prática realizada e ainda mais necessária quando se trabalha o conteúdo origem e formação do solo, pois permitiu obtermos 35 respostas satisfatórias quanto ao entendimento sobre como o solo se forma, dos 36 alunos que disseram ter compreendido esse processo (Figura 1A).

Por conseguinte, os alunos tiveram a explicação desse processo desde o intemperismo até a pedogênese, reconhecendo o solo como um elemento natural, integrante da paisagem e resultante de processos que ocorrem no ambiente. A dificuldade em lecionar sobre materiais de origem ao público de Ciência do Solo não é devida somente a essa intensa condensação de conteúdo (ZINN; SKORUPA, 2015), mas a forma como esses conceitos são apresentados no livro didático e falta de experiência do professor. Isso pode desencadear uma série de dúvidas no aluno em outros temas correlatos abordados na geografia como relevo, erosão, geomorfologia entre outros.

É importante notar que essa deficiência de conhecimento e enfoque é universal. Até mesmo em cursos de graduação e pós-graduação essa temática não é tão compreendida (ZINN; SKORUPA, 2015), o que demonstra a necessidade de buscar estratégias, ainda no ensino básico, para sanar a propagação dessa dificuldade de 
compreensão. É de suma importância que, ao abordar as temáticas aqui apresentadas, o professor possa desenvolver uma atividade prática no campo, de forma a apresentar para os alunos os fatores e processos dos ambientes diretamente envolvidos, contextualizando com a sua realidade local, integrando rocha-solo-paisagem. Não que seja uma exclusividade dos estudos e do ensino de Geografia, mas algumas ações são especialmente importantes e devem compor o eixo metodológico do professor de Geografia (GALVÃO; AFONSO, 2009), despertando o interesse dos alunos quanto à dinâmica do solo na paisagem e conduzindo-os a um posicionamento crítico frente ao processo de apropriação do espaço pelo homem.

Os componentes da paisagem referentes a Rocha silicificada da Formação Alter do Chão cretácica, Falésia de Latossolo Amarelo distrófico e Terra Preta de Índio-TPI (Solo antrópico) foram visualizados pelos alunos em campo, no contexto da explicação do conteúdo origem e formação do solo (Figuras 2 a, b e c).

Figuras $2 \mathrm{a}$, b e c - Componentes da paisagem identificados no campo para a explicação sobre o conteúdo origem e formação do solo.

(a)

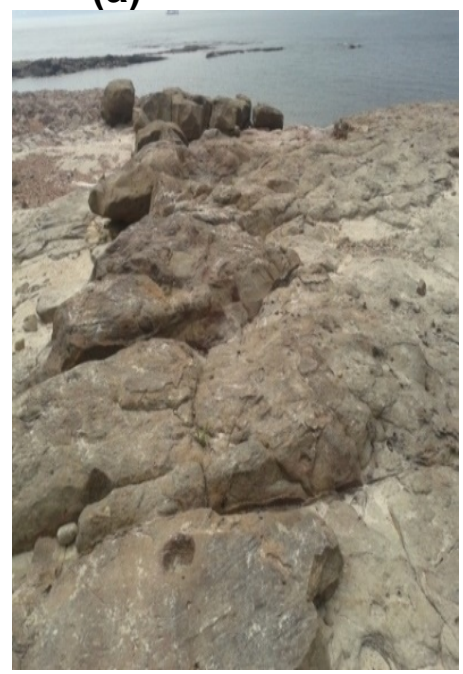

Rocha silicificada

Formação Alter do Chão (b)

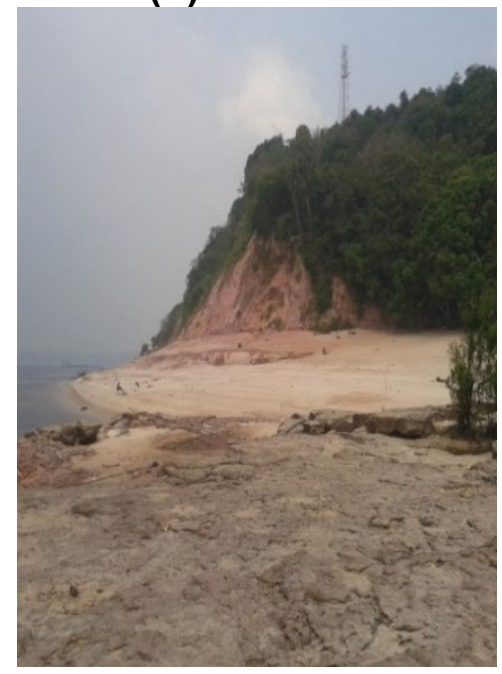

da Falésia de Latossolo Amarelo distrófico (c)

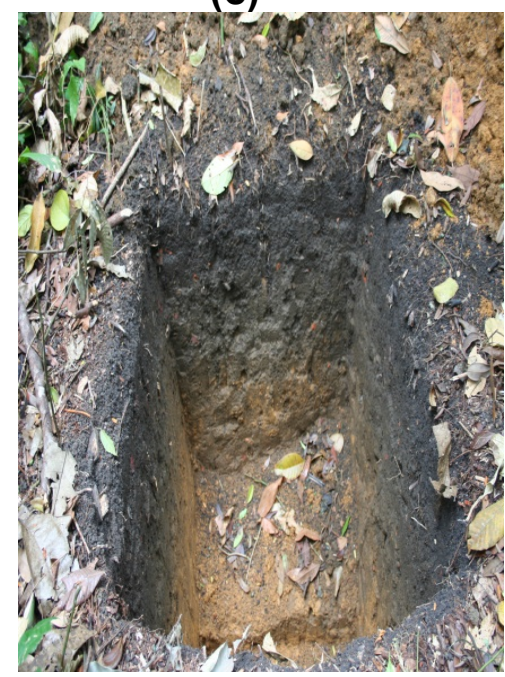

Terra Preta de Índio -TPI (Solo antrópico)

Fonte: Arquivos de imagens dos autores.

Para tanto, identificamos no ambiente, a rocha da paisagem local (Figura 2a) e o solo originado (Figura $2 \mathrm{~b}$ ), bem como um processo antropogênico, que é a formação dos solos antrópicos (Figura 2c), integrando-os a paisagem e aos processos que ocorrem no ambiente, sendo a explanação somente possível devido à realização desta atividade no campo. Se não há uma adaptação para a realidade local ou regional, o conteúdo se torna pouco atrativo para os alunos (STEFFLER; MARTINS; CUNHA, 2010). Assim, faz-se necessário repensar a prática pedagógica no sentido de problematizar o ensino do solo, alinhado à uma proposta investigativa que contribua para que o aluno valorize esse saber afim de estabelecer as relações necessárias com o contexto em que está inserido. A abordagem relacionada a MOS (Figura 1d) foi realizada comparando-se o Latossolo (Figura 2b) e o solo antrópico 
(Figura 2c), já que um dos fatores de diferenciação entre eles é a maior quantidade e qualidade da MOS, neste último. Quanto ao conceito sobre MOS, 36 alunos demonstraram sua compreensão comprovado a partir das 31 respostas satisfatórias obtidas (Figura 1d). Dada à amplitude da temática, que pode e deve ser estudada por outras áreas do conhecimento, interessa à ciência geográfica, sobretudo, conhecer a gênese, a distribuição espacial e as características do solo, visando o uso e a ocupação racional do espaço (COSTA; MESQUITA, 2010), o que os livros didáticos, a princípio, não têm alcançado. Os alunos relataram sobre seus entendimentos a respeito da MOS para os ambientes, conforme expostos na Tabela 1.

Tabela 1 - Relatos dos alunos sobre a importância da MOS para os ambientes.

\begin{tabular}{|c|c|c|c|}
\hline Categorias & Respostas & Total & $(\%)$ \\
\hline 1) Fertilidade do Solo & $\begin{array}{l}\text { "a matéria orgânica é responsável pela fertilidade do } \\
\text { solo". } \\
\text { "É o principal componente do solo, pois o deixa fértil e } \\
\text { saudável". }\end{array}$ & 10 & 29 \\
\hline $\begin{array}{l}\text { 2)Manutenção do } \\
\text { solo e da micro e } \\
\text { meso biota }\end{array}$ & $\begin{array}{l}\text { "[...] fundamental para a manutenção da micro e meso } \\
\text { biota do solo } \quad[\ldots] " .\end{array}$ & 7 & 21 \\
\hline 3)Nutrientes & $\begin{array}{l}\text { "ela possui muitos nutrientes". } \\
\text { "a matéria orgânica serve como nutriente e protege o } \\
\text { solo". }\end{array}$ & 6 & 18 \\
\hline $\begin{array}{l}\text { 4)Características } \\
\text { Físicas, Químicas e } \\
\text { Biológicas }\end{array}$ & $\begin{array}{l}\text { "a matéria orgânica tem o poder de influenciar } \\
\text { positivamente nas características físicas, químicas e } \\
\text { biológicas". }\end{array}$ & 3 & 9 \\
\hline 5)Formação do Solo & "ela ajuda na formação do solo e faz crescer plantas". & 3 & 9 \\
\hline 6)Sustento do Solo & $\begin{array}{l}\text { "[...] é ela que dá sustento a }[\ldots] \text { floresta, por a } \\
\text { Amazônia apresentar um solo pobre }[\ldots] \text { ". }\end{array}$ & 2 & 6 \\
\hline $\begin{array}{l}\text { 7)Prevenção de } \\
\text { Deslizamento }\end{array}$ & $\begin{array}{l}\text { "a matéria orgânica ajuda na prevenção de } \\
\text { deslizamentos em encostas e protege o solo contra } \\
\text { chuvas". }\end{array}$ & 2 & 6 \\
\hline 8)Sustentabilidade & $\begin{array}{l}\text { "a matéria orgânica ajuda na sustentabilidade das } \\
\text { árvores e pode ajudar na sobrevivência dos seres } \\
\text { vivos". }\end{array}$ & 1 & 3 \\
\hline
\end{tabular}

Observando os relatos dos alunos sobre a importância da MOS para os ambientes visitados durante o trabalho de campo (Tabela 1), nota-se a visão preservacionista (categoria $2(21 \%), 6(18 \%)$ e $8(3 \%))$ conservacionista $(1(29 \%), 3(18 \%)$ e $4(9 \%))$, pedológica (categoria $5(9 \%)$ ) e geomorfológica quanto a dinâmica das vertentes (categoria 7 (6\%), sobressaindo-se a 1, 2 e 3. A importância da MOS, no sentido de prevenir $\circ$ deslizamento de encostas devido a vegetação natural participar ativamente da agregação do solo evitando a erosão, salientado por $6 \%$ dos alunos, indica a compreensão obtida quanto à relação da MOS com a dinâmica das vertentes, no contexto do espaço geográfico, de forma não fragmentado entre os seus componentes e relacionado ao seu cotidiano.

Conhecer a dinâmica do espaço físico nas áreas frequentadas cotidianamente pelos 
estudantes deve ser, portanto, uma prioridade na Geografia escolar. A análise mais aprofundada dos processos físico-naturais leva ao desenvolvimento de posturas mais cautelosas em relação à ocupação (de encostas, planícies de inundação, áreas costeiras, etc.) e à interação com os elementos da natureza (chuvas, movimentos de massa, enxurradas, enchentes, estiagens, vendavais, ressacas, relâmpagos, etc). A atividade de campo favoreceu a construção de uma visão mais integrada e abrangente das questões socioambientais ao propiciar a inter-relação entre elementos físico-naturais e sociedade (COMPIANI, 2005). Cunha et al (2013), a partir de estudos realizados com experimentos, ressalta que esse tipo de estratégia didática, permitiu discutir como as características do solo (textura, estrutura, porosidade, etc.), a sua localização na paisagem (topo, média e baixa vertente) e o ciclo hidrológico devem ser considerados quando a discussão envolve o planejamento, as fragilidades e as potencialidades do ambiente, trazendo a oportunidade de relacionar algumas características pedológicas com problemas ambientais, como: erosão, compactação e assoreamento. O ensino de Geografia deve prever a construção da cidadania e conter em si a reflexão constante de uma consciência constituída sobre o ambiente vivido. Neste contexto, os professores de Geografia devem buscar conhecer ou estimular a compreensão do ambiente dos alunos, possibilitando a reflexão e a inserção deles numa sociedade que se faz pautada por direitos e deveres.

A pesquisa realizada por LIMA, DA SILVA e ARAÚJO (2018) revelou que os alunos sentem necessidade de mudanças na forma como se dá o processo de ensino e aprendizagem e que essas práticas instigam os alunos a motivarem-se e envolverem-se mais diretamente as atividades. O retorno obtido quanto às principais consequências do processo de degradação para o solo permitiu avaliar suas percepções, conforme o que consta na Tabela 2.

Tabela 2 - Relatos dos alunos sobre as principais consequências para o solo se esses ambientes forem degradados.

\begin{tabular}{llcc}
\hline \multicolumn{1}{c}{ Categorias } & \multicolumn{1}{c}{ Relatos } & Total & (\%) \\
\hline $\begin{array}{l}\text { 1. Solo Infértil } \\
\text { e Pobre }\end{array}$ & $\begin{array}{l}\text { "solo seria menos fértil". } \\
\text { "o solo se tornaria infértil, morto" }\end{array}$ & 13 & 39 \\
\hline $\begin{array}{l}\text { 2. Erosões e } \\
\text { Deslizamentos }\end{array}$ & $\begin{array}{l}\text { "[...] dependendo do local podem ocorrer diversos } \\
\text { problemas como: erosão e deslizamentos". } \\
\text { "corre o risco de o solo ficar infértil, se formarem erosões, } \\
\text { deslizamentos e etc". }\end{array}$ & 8 & 24 \\
\hline $\begin{array}{l}\text { 3. Impróprio } \\
\text { para o Cultivo } \\
\text { e Prejuízo para } \\
\text { a vegetação }\end{array}$ & "se tornaria um solo impróprio para o cultivo". & 6 & 18 \\
\hline $\begin{array}{l}\text { 4. Baixa } \\
\text { Produtividade }\end{array}$ & $\begin{array}{l}\text { "[...] o solo perde a capacidade de produção, mesmo com } \\
\text { grande quantidade de adubo". }\end{array}$ & 2 & 6 \\
\hline 5. Humana & "para os seres humanos" & 2 & 6 \\
\hline 6. Catástrofes & "ele ficará infértil, desgastado, pobre e catástrofes tanto ao & 1 & 3 \\
\hline
\end{tabular}




\begin{tabular}{llll}
\hline $\begin{array}{l}7 . \\
\text { Desertificação }\end{array}$ & "desertificação e má formação da matéria orgânica" & 1 & 3
\end{tabular}

Obs.: Dos 40 alunos da população amostral, 2 não responderam e 5 não participaram.

Fonte: Os próprios autores a partir das respostas obtidas.

A Tabela 2 demonstra as respostas dos alunos de mecânica e química sobre as principais consequências para o solo se esses ambientes fossem degradados. Categorizou-se também os relatos obtidos, obtendo-se uma visão preservacionista (categoria $7(3 \%))$, conservacionista (1 (39\%), $3(18 \%)$ e $4(6 \%))$, geomorfológica quanto a dinâmica das vertentes (categoria $2(24 \%)$, humanística (categoria $5(6 \%)$ e $6(3 \%)$, sobressaindo-se as categorias 1,2 e 3 .

Diferentemente dos resultados obtidos na (Tabela 1), percebeu-se a percepção quanto as consequências para os seres humanos (categoria 5 e 6), que nos remete quanto ao entendimento da dinâmica do solo na paisagem e um posicionamento crítico frente ao processo de apropriação do espaço pelo homem. A percepção efetiva das consequências da apropriação da natureza revelada aos alunos necessita ser feita de tal forma que possibilite sua atuação como agentes de mudança. Justen e Carneiro (2009) destacam que o ensino da geografia é de oferecer ao aluno, "desenvolvimento da capacidade de observar, analisar, interpretar e pensar criticamente, observando a realidade, tendo em vista sua transformação". Para Vigotski (2007, p. 92), "o aprendizado é mais do que a aquisição de capacidade para pensar; é a aquisição de muitas capacidades especializadas para pensar sobre várias coisas". Se a aprendizagem é a capacidade de pensar sobre várias coisas, então a aula de campo é a concretização e "organização desse aprendizado", pois ao estudarmos os conteúdos de geografia, em uma aula de campo, estamos envolvidos com os aspectos físicos, naturais, humanos, econômicos, sociais, culturais e etc.

Os tipos de erosões identificados pelos alunos foram Ravina (27 alunos), Voçorocas (26 alunos), Erosão em Sulcos (22 alunos), Erosão Laminar (14 alunos) e Erosão Pluvial (9 alunos), caracterizando, portanto, os estágios erosivos mais avançados, possíveis de serem vistos sem dificuldade. As respostas dos alunos estão coerentes com os estudos realizados a partir das aulas expositivas dialogadas sobre esta temática. No Distrito Industrial II, na Estrada do bairro de Puraquequara, foi a área onde os alunos visualizaram in loco diversos tipos de feições erosivas. A erosão Laminar é pouco perceptível, o que não desperta a atenção das pessoas, mas a exemplo dos demais processos erosivos, provocam danos ao ambiente, à medida que, aos poucos, as águas pluviais vão lavando a camada superficial do solo, expondo-a a intempéries, o que leva a ocorrer outros tipos de erosões do tipo, ravinas, sulcos, etc. Além das erosões do tipo Voçoroca e laminar, no trabalho de campo, os alunos identificaram também erosões do tipo sulco. É importante salientar que as aulas que abarcam a teoria e a prática, quando realmente trabalhadas em conjunto, podem atenuar a apatia que existe entre alguns conteúdos da Geografia, particularmente no eixo da Geografia Física. Daí a necessidade de se trabalhar com métodos inovadores e instigantes, a exemplo dos mapas conceituais, das maquetes e dos trabalhos de campo (SOUSA; JUNIOR; ALBUQUERQUE, 2019).

4


A grande evolução desses tipos de feições erosivas na cidade de Manaus deve-se aos elevados índices pluviométricos, típicos da região. A água pluvial numa terra descoberta, a gota de chuva ao cair na superfície do solo propicia o início do processo erosivo, ocasionado a separação de agregados do solo, propiciando a erosão, tendo também a ação do vento (TROEH; THOMPSON, 2007). Devido às erosões investigadas estarem expostas às elevadas temperaturas e altos índices pluviométricos, além de propiciar o avanço do processo erosivo, outras erosões poderão surgir no entorno, podendo inclusive comprometer a infraestrutura, como queda de postes de energia, queda de blocos atingindo a estrada, dentre outros. Talvez muitas das feições erosivas identificadas no campo pelos alunos já tivessem sido visualizadas por eles em algum local do ambiente, mas nunca foram valorizadas, porque não despertou neles uma preocupação quanto à importância da preservação dos solos e nem os inseriu no processo como sujeito da ação. Em campo, os alunos vivenciaram o quanto as erosões são danosas ao ambiente, com muitas consequências. A Tabela 3 retrata as respostas dos alunos quanto a este aspecto.

Tabela 3 - Consequências das erosões identificadas pelos alunos no campo.

\begin{tabular}{|c|c|c|c|}
\hline $\begin{array}{l}\text { Consequências } \\
\text { Identificadas }\end{array}$ & $\begin{array}{l}\text { Relato dos Alunos de } \\
\text { Química e Mecânica }\end{array}$ & Total & (\%) \\
\hline $\begin{array}{l}\text { Deslizamento/ } \\
\text { Soterramento de } \\
\text { Casas e Morte }\end{array}$ & $\begin{array}{l}\text { "deslizamento de terras } \\
\text { em regiões habitadas, } \\
\text { provocando } \\
\text { soterramento de casas } \\
\text { e várias mortes". } \\
\text { "deslizamentos de terra } \\
\text { ocorrem frequentemente } \\
\text { em regiões habitadas } \\
\text { provocando o } \\
\text { soterramento de casas } \\
\text { e consequente morte". }\end{array}$ & 8 & $25,0 \%$ \\
\hline $\begin{array}{l}\text { Acidente nas vias de } \\
\text { trânsito. }\end{array}$ & $\begin{array}{l}\text { "problemas para as vias } \\
\text { de trânsito, causando } \\
\text { acidentes e mortes". }\end{array}$ & 6 & $18,6 \%$ \\
\hline $\begin{array}{l}\text { Erosão/Desfiguração } \\
\text { do solo/paisagem }\end{array}$ & $\begin{array}{lrr}\text { "desgaste } & \text { do } & \text { solo, } \\
\text { desfiguração } & \text { da } \\
\text { paisagem". } & \\
\end{array}$ & 4 & $12,5 \%$ \\
\hline $\begin{array}{l}\text { Assoreamento dos } \\
\text { rios. }\end{array}$ & $\begin{array}{l}\text { "assoreamento, } \\
\begin{array}{l}\text { desgaste do solo, } \\
\text { prejuízo } \\
\text { agricultura.". }\end{array} \\
\end{array}$ & 4 & $12,5 \%$ \\
\hline $\begin{array}{c}\text { Deslizamento, } \\
\text { Desmoronamento de } \\
\text { terra }\end{array}$ & $\begin{array}{l}\text { "deslizamento e aterro } \\
\text { de terrenos". }\end{array}$ & 4 & $12,5 \%$ \\
\hline $\begin{array}{l}\text { Deslizamentos/ } \\
\text { Infertilidade do } \\
\text { Solo }\end{array}$ & $\begin{array}{l}\text { "deslizamentos, } \\
\text { infertilização do solo". }\end{array}$ & 2 & $6,3 \%$ \\
\hline $\begin{array}{l}\text { Deslizamento/ } \\
\text { Inundações }\end{array}$ & $\begin{array}{l}\text { "inundações } \\
\text { deslizamentos". }\end{array}$ & 2 & $6,3 \%$ \\
\hline $\begin{array}{c}\text { Outras } \\
\text { Consequências } \\
\text { Identificadas }\end{array}$ & $\begin{array}{lrr}\text { "ventos } & \text { e } & \text { ação } \\
\text { humana". } & & \\
\text { "circulação } & & \text { de } \\
\end{array}$ & 2 & $6,3 \%$ \\
\hline
\end{tabular}


Obs.: Dos 40 alunos, 3 não responderam e 5 não participaram) .

Fonte: Os próprios autores a partir das respostas obtidas

Nota-se que as consequências das erosões identificadas em campo, $25 \%$ e $18,6 \%$, respectivamente, deram como respostas, o deslizamento / soterramento de casas e morte e acidente nas vias de trânsito; 37,5\% citaram a Erosão/Desfiguração do solo/paisagem; Assoreamento dos rios; Deslizamento e Desmoronamento de terra, enquanto $18,9 \%$ citaram os Deslizamentos/Infertilidade do Solo e Deslizamento/Inundações, são as principais consequências. De modo geral, os alunos verificaram que as consequências das erosões são graves, comprometendo as diversas variáveis do ambiente, inclusive com possibilidades de causar danos diretos para a população. As respostas dadas pelos alunos (Tabela 3) carregam em si uma lógica e, portanto, coerência com o que foi visto e aprendido em campo, evidenciando que o suporte teórico das aulas expositivas dialogadas favoreceu o entendimento das aulas práticas. Alves et al (2014) entendem que "dentre várias técnicas utilizadas no ensino de Geografia, considera-se o trabalho de campo, uma atividade de grande importância para a compreensão e leitura do espaço, possibilitando o estreitamento da relação entre a teoria e a prática". Diante do exposto, fica claro que os trabalhos de campo são entendidos como uma metodologia investigativa e exploratória. É por meio de metodologias inovadoras que a construção do conhecimento dos alunos é adquirida (SOUSA; JUNIOR; ALBUQUERQUE, 2019).

Maio et al (2018) dizem que a "consciência e a percepção do risco não dependem unicamente da experiência e da memória pessoal de exposição ao risco. Uma outra forma de desenvolver consciência de risco e de moldar a percepção pessoal é através da criação e disseminação de informação". Ou seja, buscar ensinar o conteúdo científico com base na percepção é também uma forma de desenvolver no aluno a sua própria capacidade de percepção perante os fenômenos de magnitude destrutiva. A Tabela 4 mostra as respostas que foram dadas quanto as medidas para preservar as encostas.

Tabela 4 - Medidas para preservar as encostas segundo os alunos.

\begin{tabular}{|c|c|c|c|}
\hline $\begin{array}{c}\text { O que deve ser feito } \\
\text { quanto a: }\end{array}$ & $\begin{array}{l}\text { Relato dos Alunos de } \\
\text { Química e Mecânica }\end{array}$ & Total & $(\%)$ \\
\hline \multirow[t]{2}{*}{ Vegetação local } & $\begin{array}{l}\text { "não jogar lixo, preservar a } \\
\text { vegetação presente no local". } \\
\text { "não retirando a vegetação } \\
\text { do solo, monitorando as } \\
\text { mudanças que ocorrem no } \\
\text { solo e } \\
\text { reflorestamento nas áreas } \\
\text { devastadas" }\end{array}$ & 15 & $44,1 \%$ \\
\hline & $\begin{array}{l}\text { "Deve-se evitar construir } \\
\text { moradias e/ou fazer outros } \\
\text { tipos de obras que } \\
\text { danifiquem ou mudem o }\end{array}$ & & \\
\hline
\end{tabular}




\begin{tabular}{|c|c|c|c|}
\hline Construção de Moradias & $\begin{array}{l}\text { meio-ambiente". } \\
\text { "deve realizar urgentemente } \\
\text { a desocupação de tais } \\
\text { lugares de qualquer coisa, } \\
\text { pessoas, empresas, etc.". }\end{array}$ & 8 & $23,6 \%$ \\
\hline $\begin{array}{c}\text { Conscientização/Prevenção } \\
\text { e Conservação }\end{array}$ & $\begin{array}{l}\text { "campanhas e obras". } \\
\text { "um bom projeto de } \\
\text { conservação ambiental, que } \\
\text { a preserve, talvez por um } \\
\text { escoamento de água" }\end{array}$ & 6 & $17,6 \%$ \\
\hline Circulação de Veículos & $\begin{array}{l}\text { "Uma rota alternativa para os } \\
\text { caminhões e carros } \\
\text { pesados". }\end{array}$ & 3 & $8,8 \%$ \\
\hline Políticas Públicas & $\begin{array}{l}\text { "Os responsáveis devem criar } \\
\text { área de preservação } \\
\text { fechada". }\end{array}$ & 2 & $5,9 \%$ \\
\hline
\end{tabular}

Os relatos observados na Tabela 4 indicaram que os elevados índices pluviométricos que ocorrem na área urbana de Manaus, aliados às ações antrópicas, contribuem para o agravamento dos processos erosivos, culminando, portanto, na necessidade de adoção de medidas preventivas. Para preservar as encostas, os alunos opinaram sobre o que deveria ser feito quanto à vegetação local, a construção de moradias, conscientização/prevenção e conservação, a circulação de veículos e as políticas públicas. Um percentual de $44,1 \%$ dos alunos, quanto à vegetação local, falou da necessidade de "não jogar lixo, preservar a vegetação presente no local" e "não retirando a vegetação do solo, monitorando as mudanças que ocorrem no solo e realizando reflorestamento nas áreas devastadas".

Sobre a construção de moradia, 23,6 \% dos alunos afirmaram que "deve-se evitar construir moradias e/ou fazer outros tipos de obras que danifiquem ou mudem o meio-ambiente", "deve realizar urgentemente a desocupação de tais lugares de qualquer coisa, pessoas, empresas, etc". Nota-se que as respostas estão repletas de apelos sobre a forma negativa de como o homem exerce ações no meio, portanto, são discordantes quanto às ações antrópicas da forma como vem ocorrendo. As ações antrópicas contribuem para a desagregação de partículas do solo, provocando inúmeras consequências negativas para o ambiente. Frasson e Werlang (2010, p. 4), entendem que "[...] a poluição de origem rural ocasiona graves danos aos solos: nas áreas urbanas o lixo jogado sobre a superfície, sem o devido tratamento, é uma das principais causas dessa poluição [...]". No mesmo sentido, discorrendo sobre os processos erosivos na área urbana de Manaus, Vieira (1998, p. 39) entende que "no caso em particular da cidade de Manaus, observa-se que a influência antrópica tem, juntamente com os fatores físicos naturais, papel fundamental e até certo ponto determinante no surgimento de processos erosivos".

Em relação a Conscientização/Prevenção e Conservação, um percentual de $17,6 \%$ dos alunos citou a necessidade de "campanhas e obras", e ainda, "um bom projeto de conservação ambiental, que a preserve, talvez por um 
escoamento de água". Verifica-se que as respostas dos alunos, para fins de preservar as encostas visitadas em campo, caracterizam a percepção deles sobre o que fazer, e de certa forma, é possível compreendermos a importância do poder público e da coletividade nessas ações. Para Sousa e Matos (2012, p. 74) é importante [...] desenvolvermos de maneira satisfatória a educação em solos, trazendo à tona a importância desse recurso ao ser humano [...] e ressalta que "Embora as pessoas tenham a preocupação ambiental" [...] "a percepção do ambiente e seus componentes ainda é deficiente". Nota-se que a educação em solos é fundamental para o equilíbrio ambiental, porém, entendemos que há muito o que fazer no sentido de viabilizar uma compreensão sistêmica dos diversos elementos da paisagem. A consciência ambiental é apenas o começo, mas por si só não resolve o conhecimento do ambiente nos seus diversos níveis, contudo, a nível local, isso é possível, mesmo que parcialmente, conforme as respostas dos alunos.

Quanto à circulação de veículos e políticas públicas, um percentual de $14,7 \%$ dos alunos respondeu que para preservar as encostas deveria haver "Uma rota alternativa para os caminhões e carros pesados" e que "Os responsáveis devem criar área de preservação fechada". A partir das respostas dos alunos, é possível inferir que a prática de campo gerou conscientização ambiental, pois as medidas preventivas citadas por eles são coerentes e relevantes para a preservação das encostas. Conforme a realidade do quadro geomorfológico verificado nas áreas investigadas, as medidas preventivas, além de importantes, são necessárias, como forma de evitar o avanço destas erosões, prevenindo, portanto, parte das consequências. Guerra (2016, p. 114), entende que "[...] a partir de uma análise das características do meio físico, de uma determinada área, é possível também contribuir para o fornecimento de dados e informações que permitam a elaboração de políticas públicas, que possam, ao mesmo tempo, proteger o meio ambiente". A proteção do meio ambiente compete ao poder público e à coletividade. Nesse sentido, o estudo e compreensão da realidade local é a gênese para que o espaço planetário seja também entendido. A investigação dos processos erosivos no espaço urbano de Manaus, onde os alunos estudam e convivem uns com os outros, possibilitou que os mesmos percebessem a importância de preservar e conservar as áreas de encostas. Segundo Guimarães et al (2012, p. 9): a "sensibilização da comunidade do entorno [...] de modo que esta reconheça a importância e necessidade de se preservar a vegetação do interior e borda das voçorocas [...]" é relevante. Conhecer a realidade local sobre as voçorocas é um meio adequado para evitá-las e/ou minimizar seus avanços.

Depreende-se que a investigação realizada com os alunos resultou em experiência e vivência significativas, pois ao depararem com a realidade local, até então vista apenas nos livros e nas aulas teóricas, a ida ao campo foi determinante para eles perceberem a realidade relativa às erosões estudadas sob diversos aspectos. A partir das áreas visitadas, os alunos descreveram sobre a situação que as mesmas se encontravam, quanto ao risco de deslizamento, à destruição e degradação, à moradia, processo erosivo, vegetação, etc (Tabela 5). 
Tabela 5 - Como as áreas visitadas se encontram, segundo os alunos.

\begin{tabular}{|c|c|c|c|}
\hline $\begin{array}{c}\text { Situação } \\
\text { Identificada das } \\
\text { Áreas visitadas } \\
\text { quanto à: }\end{array}$ & $\begin{array}{l}\text { Relato dos Alunos de Química e } \\
\text { Mecânica }\end{array}$ & Total & $(\%)$ \\
\hline $\begin{array}{c}\text { Risco de } \\
\text { Deslizamento }\end{array}$ & $\begin{array}{l}\text { "com risco de deslizamento, } \\
\text { principalmente pela retirada da } \\
\text { cobertura vegetal". } \\
\text { "rachadas como se fosse ocorrer um } \\
\text { deslizamento". }\end{array}$ & 12 & $36,3 \%$ \\
\hline $\begin{array}{l}\text { Destruição e } \\
\text { Degradação }\end{array}$ & $\begin{array}{l}\text { "com sérios indícios de erosão". } \\
\text { "encontra-se em péssimo estado, pois } \\
\text { nas suas bases tinham lixo e tinha a } \\
\text { presença de pessoas, o que prejudica } \\
\text { e faz a erosão matar pessoas.". }\end{array}$ & 9 & $27,3 \%$ \\
\hline Moradia & $\begin{array}{l}\text { "as áreas se encontram habitadas e } \\
\text { até têm partes desmatadas, o que } \\
\text { facilita o deslizamento". } \\
\text { "algumas se encontram habitadas, } \\
\text { outras não, porém muito perto da } \\
\text { população". }\end{array}$ & 5 & $15,1 \%$ \\
\hline $\begin{array}{l}\text { Processo } \\
\text { Erosivo }\end{array}$ & $\begin{array}{l}\text { "a maioria estava em grande erosão". } \\
\text { "com sérios indícios de erosão". }\end{array}$ & 4 & $12,1 \%$ \\
\hline Vegetação & "secas, quentes e sem vegetação". & 2 & $6,1 \%$ \\
\hline Outras & "muitas estavam estáveis". & 1 & $3,1 \%$ \\
\hline
\end{tabular}

Obs.: dos 40 alunos, 2 não responderam e 5 não participaram.

Fonte: Os próprios autores a partir das respostas obtidas

Dentre os processos e práticas de investigação, a BNCC propõe que os alunos do ensino médio sejam levados a:

[.....] identificar problemas, formular questões, identificar informações ou variáveis relevantes, propor e testar hipóteses, elaborar argumentos e explicações, escolher e utilizar instrumentos de medida, planejar e realizar atividades experimentais e pesquisas de campo, relatar, avaliar e comunicar conclusões e desenvolver ações de intervenção, a partir da análise de dados e informações sobre as temáticas da área." (BRASIL, 2018, p.550).

Diante disso, fica patente a importância do papel do professor como mediador desse processo pedagógico, no sentido de construir um conhecimento geográfico significativo aos alunos, em vista de uma sociedade mais humanizada. Portanto, o conhecimento geográfico torna-se relevante aos educandos, na medida em que possibilita a reflexão crítica sobre a complexidade do mundo, em suas múltiplas dimensões locais e globais, tendo como pressuposto básico a visão relacional da realidade-mundo, nas interconexões das "[...] partes e o todo, o todo e as partes, as partes entre si" (Morin, 2000, p. 38).

Em relação ao risco de deslizamento, destruição e degradação, 63,6\% dos alunos afirmaram que as áreas erosivas estão "com risco de deslizamento, principalmente pela retirada da cobertura vegetal" e também estão "rachadas 
como se fosse ocorrer um deslizamento", "com sérios indícios de erosão" e "encontra-se em péssimo estado, pois nas suas bases tinham lixo e tinha a presença de pessoas, o que prejudica e faz a erosão matar pessoas. "Conforme as respostas obtidas observam-se que 0 desmatamento contribui significativamente para o agravamento do processo erosivo. Portanto, os fatores antrópicos aliados aos fatores naturais têm papel fundamental nos processos erosivos de Manaus e as ações humanas realizadas de forma incorreta agravam esse quadro que, conforme os estudos já realizados apresentam dados preocupantes. Sobre moradia, $15,1 \%$ dos alunos afirmaram que "as áreas se encontram habitadas e até têm partes desmatadas, o que facilita o deslizamento" e que "algumas se encontram habitadas, outras não, porém muito perto da população". Novamente o desmatamento é citado pelos alunos e é uma causa que contribui para o deslizamento, pondo em risco a integridade física da população que mora nas proximidades. Quanto ao processo erosivo, 12,1\% dos alunos afirmaram que "a maioria estava em grande erosão" e "com sérios indícios de erosão". As respostas dos alunos espelham a realidade existente nas áreas visitadas, onde os processos erosivos encontram-se num estágio bastante avançado, com visíveis riscos de deslizamentos.

No que se refere à vegetação e outros aspectos, os alunos, num percentual de 9,2\% afirmaram que as áreas estavam "secas, quentes e sem vegetação" e "muitas estavam estáveis". Nota-se que as respostas dos alunos, de modo geral, convergem para as ações antrópicas e suas consequências junto aos processos erosivos visitados por eles, o que de certa forma, tem coerência com os autores que já realizaram estudos correlatos aqui na capital do estado do Amazonas. Albuquerque e Vieira (2014, p. 253), afirmam que "[...] topos planos e encostas convexas de grande declividade tornam-se ambientes naturalmente suscetíveis à ocorrência de processos erosivos intensos em Manaus, principalmente quando aliados à intervenção antrópica [...]". Verificamos que os alunos identificaram inúmeros aspectos que caracterizam a situação das erosões visitadas, de acordo com às orientações metodológicas, configurando, portanto, uma aprendizagem satisfatória, pois, apenas $3,1 \%$ deles, correspondente a 1 aluno, demonstrou equívoco gramatical no relato "muitos estavam estáveis", mas acredita-se que na verdade, o que ele quis dizer, ao referir-se à situação em que as áreas visitadas se encontravam era que muitas estavam instáveis.

A Tabela 6 demonstra o entendimento dos alunos sobre o que deve ser feito para evitar deslizamentos nas encostas, quanto à moradia e ocupação, preservação e tratamento de solo, vegetação local, circulação de veículos e conscientização.

Tabela 6 - O que deve ser feito para evitar deslizamentos nas encostas, segundo os alunos.

\begin{tabular}{|c|c|c|c|}
\hline $\begin{array}{l}\text { O que deve ser } \\
\text { feito quanto à: }\end{array}$ & $\begin{array}{c}\text { Relato dos Alunos da Química e } \\
\text { Mecânica }\end{array}$ & Total & (\%) \\
\hline $\begin{array}{l}\text { Moradia e } \\
\text { Ocupação }\end{array}$ & $\begin{array}{l}\text { "devem ser desocupadas e feitas as } \\
\text { devidas barragens, etc." } \\
\text { "evitar a moradia das pessoas } \\
\text { naquela área". }\end{array}$ & 14 & $46,6 \%$ \\
\hline
\end{tabular}




\begin{tabular}{|c|c|c|c|}
\hline $\begin{array}{l}\text { Preservação e } \\
\text { Tratamento do } \\
\text { Solo }\end{array}$ & $\begin{array}{l}\text { "reconstrução dos solos com bastante } \\
\text { liteira para absorver a água". } \\
\text { "criação de um projeto para } \\
\text { conservação do ambiente". }\end{array}$ & 5 & $16,7 \%$ \\
\hline Vegetação local & $\begin{array}{l}\text { "não remover mais a cobertura } \\
\text { vegetal, plantar mais árvore ou } \\
\text { desocupar o local". } \\
\text { "plantio de vegetação e observação". }\end{array}$ & 5 & $16,7 \%$ \\
\hline $\begin{array}{l}\text { Circulação de } \\
\text { Veículos }\end{array}$ & $\begin{array}{l}\text { "mudar a área da circulação de } \\
\text { automóveis e pessoas". } \\
\text { "rotas alternativas e restrições de } \\
\text { alguns veículos". }\end{array}$ & 4 & $13,3 \%$ \\
\hline Conscientização & $\begin{array}{l}\text { "conscientizar os alunos do perigo". } \\
\text { "manter campanhas educativas } \\
\text { permanentes, que esclareçam a } \\
\text { população sobre os perigos } \\
\text { implicados e os hábitos [...]". }\end{array}$ & 2 & $6,7 \%$ \\
\hline
\end{tabular}

Com relação a moradia e ocupação, preservação e tratamento do solo, $63,3 \%$ disseram que as áreas "devem ser desocupadas e feitas as devidas barragens, etc." e "evitar a moradia das pessoas naquela área", e a "reconstrução dos solos com bastante liteira para absorver a água", e ainda, a "criação de um projeto para conservação do ambiente". Os relatos não deixam dúvidas, ao constatarem que as áreas visitadas se encontram numa situação erosiva que continua avançando e degradando o ambiente, e, portanto, comprometendo a qualidade ambiental local e do entorno, carecendo, portanto, de conservação do solo. Quanto a vegetação local, a circulação de veículos e a conscientização, num percentual de 36,4\% opinaram para "não remover mais a cobertura vegetal, plantar mais árvore ou desocupar o local" e "plantio de vegetação e observação", a necessidade de "mudar a área da circulação de automóveis e pessoas" e "rotas alternativas e restrições de alguns veículos", "conscientizar os alunos do perigo" e "manter campanhas educativas permanentes, que esclareçam a população sobre os perigos implicados e os hábitos [...]".

Constatamos que o entendimento dos alunos sobre as medidas para evitar deslizamentos nas áreas de encostas está coerente com as discussões realizadas durante as aulas expositivas dialogadas, pois, em campo, puderam visualizar o ambiente, suas complexidades, e principalmente, as condições em que as áreas erosivas se encontram, considerando as ações antrópicas e as diversas variáveis ambientais (solo, vegetação, geomorfologia, clima, etc.). Lopes e Melo (2017) destacam que o aluno deve ter a oportunidade de entender o espaço geográfico por meio de uma construção histórico-social, unindo as relações estabelecidas entre sociedade, espaço e natureza, constituindo uma conscientização e criticidade inerente aos problemas sociais, econômicos e ambientais que circundam o espaço.

\section{Considerações finais}

A prática de campo de caráter investigativo, exploratório e interdisciplinar possibilitou o ensino de origem, formação, ocupação, erosão e preservação do solo de forma

4


prática, no campo, permitindo aos estudantes compreender os processos, transformações e interações que regem essas temáticas, impossíveis de serem compreendidas apenas em sala de aula, propiciando uma experiência capaz de desvendar o ambiente no qual os alunos estão inseridos.

Por conseguinte, a partir da organização, análise e interpretação dos dados, consubstanciados no referencial teórico e metodológico, observamos o despertar nos alunos de atitudes, habilidades, posicionamentos e competências quanto à preservação e conservação do solo, bem como frente aos processos, dinâmicas e transformações observadas ao longo do desenvolvimento das atividades práticas realizadas.

Os professores precisam conduzir o ensino a partir de um processo dinâmico e não isolado em conceitos específicos da ciência do solo, mas contextualizado com a paisagem e com os fatores e processos atuantes.

Por isso, faz-se necessário repensar a prática pedagógica no sentido de problematizar o ensino do solo no campo, a fim de estabelecer relações necessárias com o contexto regional favorecendo valores sociais e ambientais.

\section{Referências}

ALVES, A.O.; SOUZA, M.I.A. A geografia nos anos iniciais: a leitura integrada da paisagem para a construção de conceitos dos conteúdos relevo-solo-rocha. Revista Brasileira de Educação em Geografia, v. 5, n. 10, p. 277-299, jul./dez., 2015. Disponível em:

$<$ http://www.revistaedugeo.com.br/ojs/index.php/revistaedugeo/article/viewFile/329/17>.Aces so em: 29 jan. 2020.

ALVES, C.C.; BRAGA, M.B.C.; TAVARES, F.J.R. Formação de professores reflexivos no Brasil: aspectos teóricos e legislativos. In: FÓRUM INTERNACIONAL DE PEDAGOGIA, 6., 2014, Santa Maria. Anais eletrônicos... Santa Maria: FIPED, 2014. Disponível em: <http://editorarealize.com.br/revistas/fiped/anais.php>. Acesso em: 20 jan. 2020.

ARRUDA, E.A. A cidade é a sala de aula: ensinar/aprender geografia a partir do lugar. Geosaberes, v. 10, n. 22, p. 238-252, 2019.

BERTRAND, G. Paysage et géographie physique globale: Esquisse méthodologique. Persee.fr, Toulouse, v. 39, n. 3, p. 249-272, 1968. Revue Géographique des Pyrénées et du Sud-ouest. <http://www.persee.fr/docAsPDF/rgpso_00353221_1968_num_39_3_4553.pdf> Acesso em: 15 jan. 2020.

BOGDAN, R.; BIKLEN, S. Características da investigação qualitativa. In: Investigação qualitativa em educação: uma introdução à teoria e aos métodos. Porto: Porto Editora, 1994. p. 47-51. 
BRAGA, K. da C.; OLIVEIRA, B.S. de; MORAIS, E.G. Desafios e contribuições da aula de campo em escola pública de Altamira-Pará. Geosaberes, Fortaleza, v. 8, n. 14, p. 16-34, 2017.

BRASIL. Ministério da Educação. Secretaria Executiva. Base Nacional Comum Curricular: Brasília, 2018.

Disponível em: <http://download.basenacionalcomum.mec.gov.br/>. Acesso em: 5 jan. 2020.

COMPIANI, M. Geologia/Geociências no Ensino Fundamental e a Formação de Professores. Revista do Instituto de Geociências USP, São Paulo, v. 3, p. 13-30, set. 2005. Disponível em: <www.igc.usp.br/geologiausp>. Acesso em: 28 dez. 2019.

COSTA, A.A. da; MESQUITA, M.L.de. Solos e ensino: a proposta dos livros didáticos de geografia e dos parâmetros curriculares nacionais. In: ENCONTRO NACIONAL DOS GEÓGRAFOS: Crise, práxis e autonomia: espaços de resistência e de esperanças Espaço de Diálogos e Práticas, 16., 2010, Porto Alegre. Anais... Porto Alegre: Mediação, 2010.

Disponível em: <http://www.agb.org.br/xvieng/anais/index.html>. Acesso em: 18 dez. 2019.

FRASSON, V. da R.; WERLANG, M. K. Ensino de solos na perspectiva da educação ambiental: contribuições da ciência geográfica. Geografia: Ensino \& Pesquisa, Santa Maria, v. 1 4, n. 1, p. 94- 99, 2010.

Disponível em: <https://www.ige.unicamp.br/pedologia/ensino\%20de\%20solos.pdf>. Acesso em: 30 dez. 2019.

FRANZINELLI, E.; IGREJA, H. Sítios geológicos e Paleontológicos do Brasil. Brasília: CPRM, 2013. p.1-20.

FREITAS, A.C. de. Experimentos alternativos para determinação da qualidade da água a partir da utilização de filtros de garrafas de PET. Educitec, Manaus, v. 04, n. 08, p. 279-294, nov. 2018.

GALVÃO, C. F.; AFONSO, A. E. A Geografia e os ciclos. Rio de Janeiro: Secretaria Municipal de Educação da Cidade do Rio de Janeiro, 2009.

GODOY, A.S. Pesquisa qualitativa: tipos fundamentais. Revista de Administração de Empresas, São Paulo, v. 35, n. 3, p. 20-29, 1995.

GUERRA, M.D.F.; SOUZA, M.J.N. de; LUSTOSA, J.P.G. Revisitando a teoria geossistêmica de bertrand no século XXI: aportes para o GTP. Geografia em questão, v. 5, n.2, p. 28-42, 2012.

GUERRA, A.J.T. Erosão dos solos e movimentos de massa: abordagens geográficas. Curitiba: CRV, 2016.

GUIMARÃES, J.C.C.; ALMEIDA, W.F. de; PAIS, P.S.M.; ANDRADE, M.L. de C. Abordagem de práticas conservacionistas na recuperação de voçorocas. Enciclopédia Biosfera, Centro Científico Conhecer - Goiânia, v. 8, n. 14., 2012. Disponível em:

<http://www.conhecer.org.br/enciclop /2012a/ambientais/abordagem.pdf>. Acesso em: 22 jan. 2020.

JUSTEN, R.; CARNEIRO, C.D.R. Importância dos Trabalhos de Campo na Disciplina Geografia: Um Olhar Sobrea Prática Escolar em Ponta Grossa (PR). In: $10^{\circ}$ Encontro 
Nacional de Prática de Ensino em Geografia, 2009, Porto Alegre. Anais eletrônicos... Porto Alegre: UFRGS, 2009.

Disponível em: <http://www.agb.org.br/XENPEG/artigos/GT/GT4/tc4\%20(64).pdf>. Acesso em: 28 jan. 2020.

LOPES, G.T.; MELO, J.A.B. de. Estratégias didáticas para a compreensão dos conteúdos nas aulas de geografia. Geosaberes, Fortaleza, v. 8, n. 16, p. 2-11, 2017.

LIMA, A.E.R.; SILVA, D.R. da; ARAÚJO, E.F. de. Metodologias ativas em geografia: experiências docentes do instituto federal de educação, ciência e tecnologia do Ceará (IFCE). Geosaberes, v. 9, n. 18, p. 1-13, 2018.

MAIO, R.; FERREIRA, T. M.; VICENTE, R. O papel da perceção e comunicação na mitigação do risco de terramoto. Territorium, v. 25, n. 2, p. 69-78, 2018.

MORIN, E. Os Sete Saberes Necessários à Educação do Futuro. 2.ed. São Paulo: Cortez/Unesco, 2000.

MUGGLER, C.C.; SOBRINHO, F. de A. S.; MACHADO, F. A. Educação em solos: princípios, teoria e métodos. Revista Brasileira de Ciência do Solo, Viçosa, v. 30, p. 733740, 2006.

NASCIMENTO, F.R. do; SAMPAIO, J.L.F. Geografia física, geossistemas e estudos integrados da paisagem. Revista da casa da geografia de Sobral, v. 7, p. 167-179, 2005.

NUNES, H.K. de B.; SOUSA, S.R.C.T de; VIANA, A.I.G. Atividades de campo e formação de professores de geografia em uma universidade do Piauí. Geosaberes, Fortaleza, v. 9, n. 19, p. $1-14,2018$.

PRADO, C.J.B. do; CARNEIRO, S.M.M. Livro Didático de Geografia: estudo da linguagem cartográfica. Educação \& Realidade, Porto Alegre, v. 42, n. 3, p. 981-1000, 2017.

SOUSA, L.M.S.; ALBUQUERQUE, E.L.S. Google Earth e ensino de cartografia: um olhar para as novas geotecnologias na Escola Santo Afonso Rodriguez, município de Teresina, estado do Piauí. Geosaberes, Fortaleza, v. 8, p. 94-104, 2017.

SOUSA, M.G. de; JUNIOR, I. de O.C; ALBUQUERQUE, E.L.S. Aulas de geografia física e metodologias aplicáveis ao ambiente escolar. Geosaberes, v. 10, p. 81-90, 2019.

STEFFLER, M.; MARTINS, V. M.; CUNHA, J. E. O solo como instrumento de educação ambiental. In: Encontro Nacional dos Geógrafos, 2010, Porto Alegre. Anais do XVI Encontro Nacional dos Geógrafos. Porto Alegre, 2010.

TROEH, F. R.; THOMPSON, L. M. Solos e fertilidade do solo. 6. ed. São Paulo: Andrei, 2007.

VIGOTSKI, L.S. A Formação Social da Mente: o desenvolvimento dos processos psicológicos. In: COLE, M.; JOHN-STEINER, V. (Org.). Tradução NETO, J. C.; BARRETO, L. S. M.; AFECHE, S.C. 7.ed. São Paulo: Martins Fontes, 2007. Cap. 6, p. 88-105. 
VIEIRA, L.S.; SANTOS, P.C.T.C. dos; VIEIRA, N.F. Solos: propriedades, classificação e manejo. Brasília: MEC/ABEAS, 1988. (Programa Agricultura nos Trópicos, 02).

ZINN, Y.L.; SKOPURA, A.L.A. Uma nova abordagem para o ensino sobre materiais de origem do solo. Cadernos de Ciência \& Tecnologia, Brasília, v. 32, n. 1/2, p. 229-244, 2015.

Recebido: 04/02/20

Aprovado: 22/04/20

Como citar: MARQUES, J.D.; BOTELHO, J. S. O ensino de solo na geografia a partir da prática de campo. Revista de Estudos e Pesquisa sobre Ensino Tecnológico (EDUCITEC), v. 6, Edição Especial, e098620, 2020.

Direito autoral: Este artigo está licenciado sob os termos da Licença Creative CommonsAtribuição 4.0 Internacional. 